\title{
Study on Transverse Strength of the Deck-Container Ships Due to Laying All Containers on Deck
}

\author{
Rosmani $^{\mathrm{a}}$, Andi Ardianti ${ }^{\mathrm{b} *}$, Ganding Sitepu ${ }^{\mathrm{c}}, \operatorname{Hamzah}^{\mathrm{d}}$, Andi Mursyid Nugraha ${ }^{\mathrm{e}}$, Muhammad Ichsan Hayatuddin ${ }^{\mathrm{f}}$ \\ a'Department of Naval Architecture, Engineering Faculty, Hasanuddin University. Email: rosmanimunandar@ymail.com \\ bepartment of Naval Architecture, Engineering Faculty, Hasanuddin University. Email: aardianti@ gmail.com \\ 'Department of Naval Architecture, Engineering Faculty, Hasanuddin University. Email: sitepu.unhas@ gmail.com

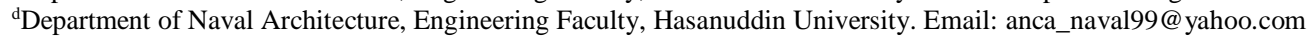 \\ ${ }^{\mathrm{e}}$ Department of Naval Architecture, Engineering Faculty, Hasanuddin University. Email: andi.mursid08@ gmail.com \\ fDepartment of Naval Architecture, Engineering Faculty, Hasanuddin University. Email: ichsan.hayat13@gmail.com
}

\begin{abstract}
The strength of transversal structure of the ship has a great effect on the safety of the ship. Ships will experience conditions that affect the strength of the ship's structure. Deck-Container ships are the ships that all containers are loaded on deck such as MV. Khendaga Nusantara series ships. The transversal strength of the ships is loaded mainly by the weight of cargo laying on the deck. This research aims to determine the transverse strength of a deck-container ship due to all container loads on deck. The research was done by using finite element method through modeling transverse ship structure, the simulation is conducted by varying the amount and layout of containers on deck. The loads applied to the model are side loads, bottom loads, and deck loads according to BKI rules. The results show that the stress that occurred in the web frame was $140.63 \mathrm{~N} / \mathrm{mm}^{2}$ due to the placement of the entire container on the deck (full loading). For ship structure response, a deformation of $2.86 \mathrm{~mm}$ occurred in the web frame area at maximum loading. Stress ratio that occurs in all ship's structures does not exceed 1 in other words the working stress does not exceed the allowed stress according to BKI rules.
\end{abstract}

Keywords: Container deck; FEM; stress; transversal strength

\section{Introduction}

Nowadays, transportation by using ships has become an important aspect in the field of transportation. There is an increasing need for transportation of logistics goods to natural resources in various places, especially in the island's areas. Sea transportation is considered the most efficient because it can carry large amounts of cargo and is also the most economical because of the lower costs than other modes of transportation.

In carrying out its operational activities, the ship will experience various conditions that can affect the strength of the ship's structure, whether it is caused by weather, sea waves, or internal factors such as the weight of the ship itself, load weight, or load shifting. As for the loads that work on the ship include load on deck, load on ship side, and load on ship bottom. The strength of construction is one of the technical aspects that plays a very important role in fulfilling the safety of ships when sailing. A ship is eligible for the technical factors if the maximum stress that occurs in

\footnotetext{
${ }^{*}$ Corresponding author. Tel.: +62 8128785620

Jalan Poros Malino km. 6 Bontomarannu
}

Gowa, Sulawesi Selatan, Indonesia, 92171 the ship's structure during critical conditions is still smaller than the maximum stress of the material used as a component of the construction of the ship.

Ships with large loads, such as containers, will receive heavy loading on the deck structure due to the weight of the cargo, so it is very important to analyze the transverse strength of the deck structure. KM. KHENDAGA NUSANTARA 11 is a type of container ship that only loads containers on the deck and the space under the deck of the ship is left empty. Laying this load will automatically affect the strength of the ship construction, primarily on the transverse strength of the ship. So as to find out whether the ship construction still meets the requirements and to anticipate the failure of the ship structure due to the load laying system on the ship, this study was conducted to analyze the transverse strength of the ship due to laying containers only on the deck of the ship. 


\section{Literature Review}

\subsection{Container ships}

Container ships are cargo ships that are designed to transport cargo in containers [1]. The engine room and accommodation room are usually located at the rear so that the maximum length of the hull can be used for container storage. To avoid the container that is on the deck moving or falling into the sea during shipping, the container is bound to the ship.

Containers are reusable boxes made of steel or aluminum. Containers made in various types and sizes. Normal dimensions include lengths of 20, 40 and 45 feet, a width of 8 feet, and height of 8.5 or 9.5 feet. The internal volume and weight of goods that are usually carried vary according to the material [2].

In practical applications, container loads are usually assumed to consist of three loads namely the static weight of the container in perpendicular conditions, the addition of static loads due to rolling and pitching of the ship, and the inertia due to ship acceleration.

\subsection{The ships transverse construction}

The transverse construction components of the ship include deck beams, frames, Wrang (floor) and others. The transverse construction of the ship consists of frames as a place to attach the skin of the ship and it is reinforced with side strings. Installation of this transverse construction, the frame is formed rotating and covered with plates and supported by side stringer that installed horizontally.

\subsection{The ships transverse strength}

The transverse strength of the ship is the ability of the transverse structure of the ship to maintain the crosssectional shape against interference with loads acting on the ship such as loads on the deck, loads on the sides, and loads on the bottom. So it is clear that the main components of the ship's structure are the bottom structure, the side structure, and the deck structure [1].

Loads that may influence of local structure and must be taken into account in the design of the transverse construction of the ship consists of two parts, namely: buoyancy, and gravity. The upward pressure is resultant from the distribution of hydrostatic pressure in the outer plane of the dipped ship hull. Gravity is the largest downward force on ships and its contents [3]. As a result of these loads, all parts of ship construction experience some type of stress. There are several factors that cause the actual or different stress distribution to occur from the ideal stress distribution. Because of the transverse shear stress, distortion occurs based on the length of the cross-section of the hull girder [4]. In this research, the vertical strength of the ships was calculated according to BKI Rules Vol. II [5].

\subsection{Stress and Strain}

Stress is defined as the amount of force acting per unit area. Mathematically formulated as Eq. 1 as follows:

$$
\sigma=\frac{F}{A}
$$

Where, $\sigma$ is stress $\left(\mathrm{N} / \mathrm{mm}^{2}\right), \mathrm{F}$ is force or load $(\mathrm{N})$ and $\mathrm{A}$ is face area $\left(\mathrm{mm}^{2}\right)$. There are two types of stress: normal stress and shear stress. Normal stress $(\sigma)$ is normal force or axial force per unit area [6].

Strain is expressed as the increase of length per unit length. Strain can be written as Eq. 2 as follows :

$$
\varepsilon=\frac{\Delta L}{L}
$$

Where, $\varepsilon$ is strain $\left(\mathrm{N} / \mathrm{mm}^{2}\right), \Delta \mathrm{L} \quad$ is the total of length increase $(\mathrm{mm})$ and $\mathrm{L}$ is initial length $(\mathrm{mm})$. Hooke's law states that within certain limits, the stress on the material is directly proportional to the strain.

Stress is static amounts; it is a measure for pressure on structural materials. On the other hand, strains are kinematic amounts; it measures structural deformation. However, deformation depends on the load acting on the structure. Therefore, stress and strain are not independent. The physical relationship that links this number is called constitutive law. This describes the behavior of structures material under load. It depends on the material and can only be obtained with the help of experiments [7].

One of the most important experiments to find the relationship between stress and strain is the tension or compression test. Here, small specimens of material are placed into the test machine and are elongated or shortened. The force $\mathrm{F}$ applied by the machine to the specimen can be read at the engine speed; That causes normal stress $\sigma=F$ / $A$. The change of $\Delta l$ from the length of the specimen can be obtained and strain can be measured by using $\varepsilon=\Delta l / l$.

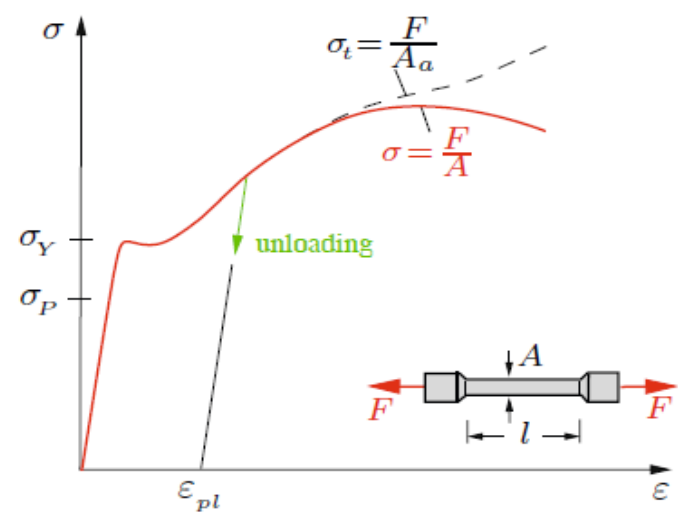

Figure 1. Stress-Strain curve [7] 
The graph of the relationship between stress and strain is shown schematically (not scaled) for the steel specimen in Fig. 1. This graph is called a stress-strain diagram. The graph shows that for small values of strain, the relationship is linear (straight line) and the stress is proportional to the strain. This behavior applies until the stress reaches the proportional limit $\sigma_{P}$. If the stress exceeds the proportional limit, the strain begins to increase faster and the slope of the curve decreases. This continues until the stress reaches the yield stress $\sigma_{Y}$. From this point, the stress-strain diagram shows that strain increases at constant stress. Note that many materials do not show clear results points. At the end of the slope, the curve increases again which indicates that the material can maintain an additional load. This phenomenon is called strain hardening.

\subsection{Permissible stress}

Permissible stress is the stress that causes a construction to experience a large deflection. The deflection is the limit of construction that still safe to overcoming the load that occurring or working on it.

The stress acting on the structure can be evaluated by using the value of the permissible stress issued by the classification bureau which is $150 / \mathrm{k}\left[\mathrm{N} / \mathrm{mm}^{2}\right]$. If the working stress that occurs in the conditions of loading, the vertical bending moment exceeds the permissible stress, the structure or object of the research is in an unsafe condition and if the working stress value is less than the value of the permissible stress, the structure is in a safe condition or meets the rule's standards.

Based on BKI rules, the normal strength of the steel hull structure is that the hull steel structure has a yield point of $\mathrm{REH}=235 \mathrm{~N} / \mathrm{m}^{2}$ and tensile strength $\mathrm{Rm}=400-520 \mathrm{~N} / \mathrm{m}^{2}$.

\subsection{Finite Element Method}

Finite Element Method is a numerical method used to solve technical and mathematical problems of a physical phenomenon. The types of physical and mathematical problems that can be solved by finite element methods are structural and non-structural analysis. The type of structural analysis problem includes stress analysis, buckling and vibration analysis. The type of non-structures analysis includes heat and mass transfer, fluid mechanics, and the potential distribution of electricity and magneticity [8].

By using the Finite Element method, all the complexity of the problem, such as various forms, boundary conditions and loads are maintained but the solutions obtained are estimates. This is because of its diversity and flexibility as an analytical tool. Quick improvements in computer hardware technology and reduced computer costs have driven this method because computers are a basic need for the application of this method. A number of popular brand element analysis packages are now commercially available to simplify a complex structure analysis [9]. Some popular packages for FEM are STAAD-PRO, GT-STRUDEL, NASTRAN, NISA, and ANSYS.

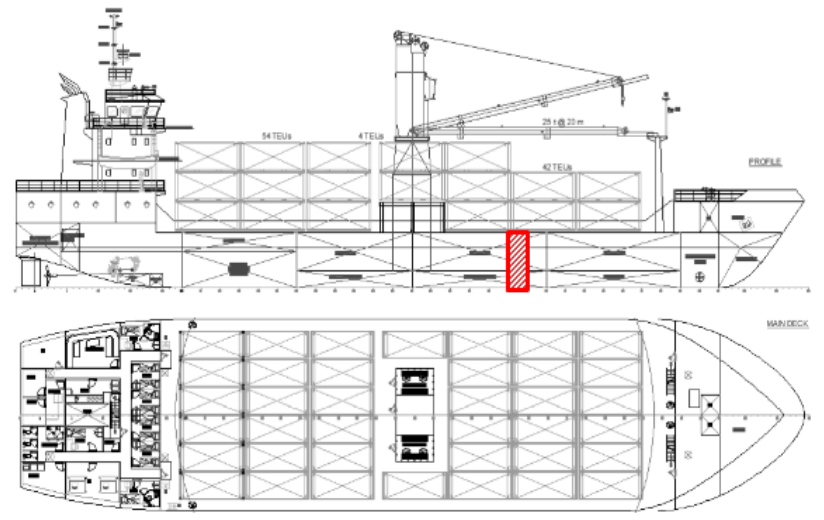

Figure 2. General arrangement

\section{Research Methodology}

\subsection{Models data}

The object in this study is the transverse construction of container ships of KM Khendaga Nusantara 11 with data as follows:

$\begin{array}{ll}\text { Type of Ship } & : \text { Container } \\ \text { LOA } & : 74.05 \mathrm{~m} \\ \text { LBP } & : 69.22 \mathrm{~m} \\ \text { B } & : 17.2 \mathrm{~m} \\ \text { H } & : 4.9 \mathrm{~m} \\ \text { T } & : 3.7 \mathrm{~m} \\ \text { DWT } & : 3327 \mathrm{Ton}\end{array}$

The ship loads containers only on decks with a capacity of 100 units and weighs 24 tonnes per unit. For more details, they can be seen in Fig. 2.

Figure 2 show general arrangement of ships. It can be seen that this ship has a unique construction that is loading all container only on the deck and below the deck consists of void tanks. The shaded part in the Fig. 2 is the ships part that will be modeled in this study. From the general arrangement, it can be seen that in frames 40 - 41, the distance of the frame is one of the most critical parts because this section holds the weight of three stack containers or 15 container units.

The planning of container loading at KM. Khendaga Nusantara 11 is based on the container stowage plan or Bayplan principle as shown in Figure 3.

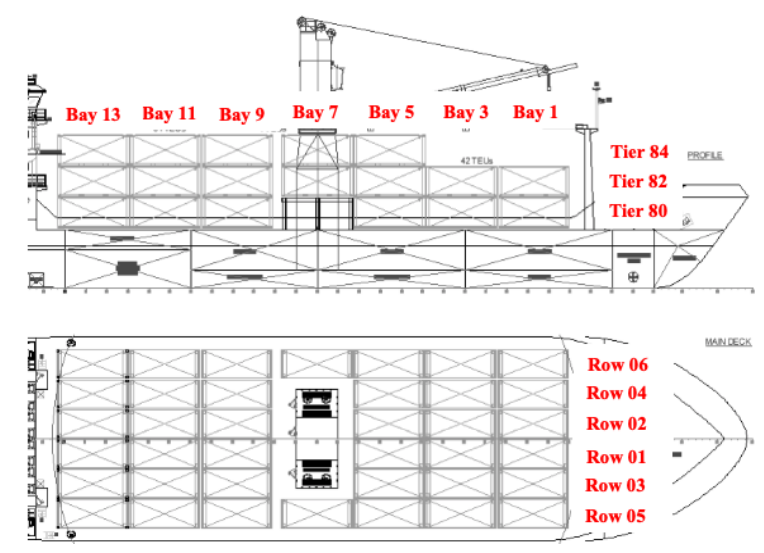

Figure 3. Container loading plan (bayplan) 


\subsection{Structure modeling}

The aim of this study is to analyze the transverse strength of the ship, so in modeling the transverse structure of the ship is strived to be the same as the actual conditions such as the midship construction as shown in Fig. 4. The shape and arrangement of the transverse construction framework are analyzed based on the form of the installed construction, namely:

a. The structure being modeled starts from frames 40 to 41 , where the distance between frames is $1800 \mathrm{~mm}$ and the width of frames is $17200 \mathrm{~mm}$.

b. The type of construction used is longitudinal construction so that the number of modeled frames are 4 web frame, 4 longitudinal deck girder, 24 longitudinal deck beam, 10 side longitudinals, 22 longitudinal bottom, and 8 pillars, where the distance between frames is $600 \mathrm{~mm}$.

c. The ship structure component that is modeled is a component that has an important role in the elongated strength of the ship.

d. This model uses the $\mathrm{x}, \mathrm{y}$, and $\mathrm{z}$ axes. The positive $\mathrm{x}$-axis shows the width of the model from the left side of the hull to the right side of the hull, the positive y-axis shows the height of the ship from the baseline to the deck of the ship, and the z-axis shows the length of the ship from frame number 40 to number 41 .

e. The type of element used is the shell element type 281 . The type was chosen because it is more suitable for modeling plates and has six degrees of freedom for each node. In addition, this type allows analysis of threedimensional stresses that occur on the $\mathrm{x}, \mathrm{y}$, and $\mathrm{z}$ axes.

f. Mounting the pedestal on the model is done at the neutral axis of the transverse construction of the ship. Restraints given at that point are restraints on translational $\mathrm{x}$, translation $\mathrm{y}$, translation $\mathrm{z}$, rotation $\mathrm{x}$, rotation $\mathrm{y}$, and rotation $\mathrm{z}$.

The ship construction framework is then modeled in 3D, the results of the modeling can be seen in Figure 5. In the model, the geometry is measured by matching all the coordinates that have been made in accordance with the actual geometry.

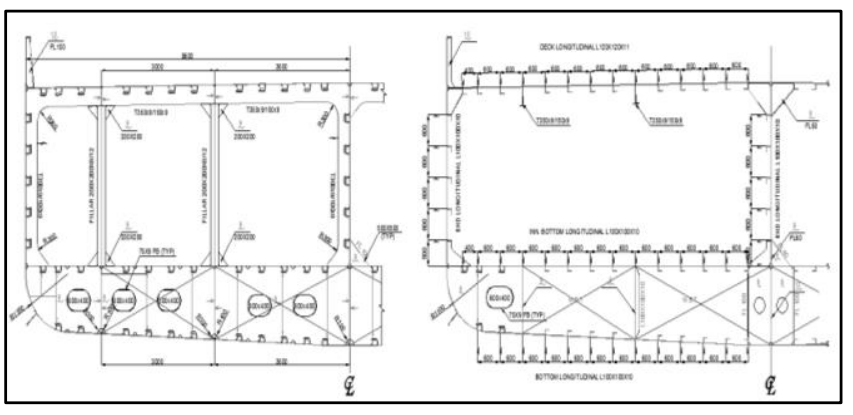

Figure 4. Midship construction

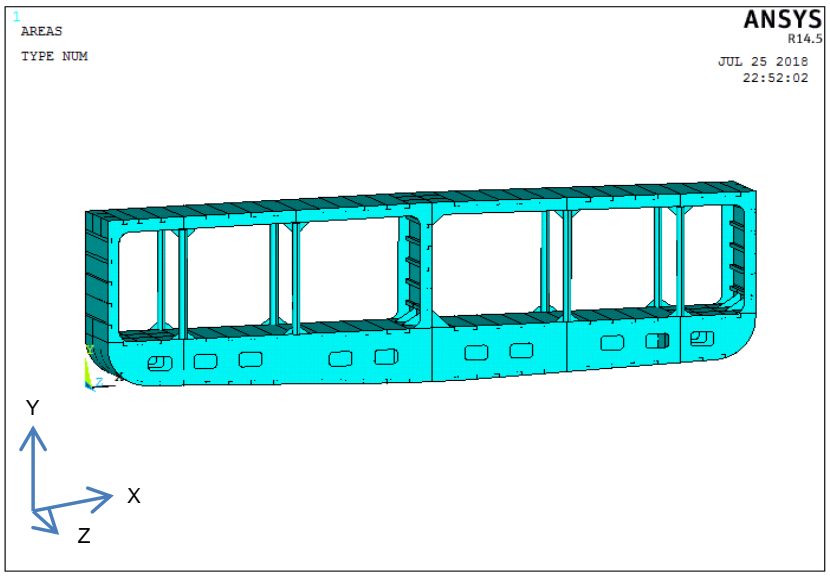

Figure 5. Numerical model

\subsection{Load distribution}

Calculation of the load distribution is conducted to divide the magnitude of the force with respect to the points (nodes) of the load on the deck, the bottom, and the sides of the ship. In this research, the input load is the side load where the center is located below or above the surface of the water where the wave direction is transverse to the ship's speed, the ship's bottom load, the weather deck load and the load of loads. Load input is done by changing the unit load from $\mathrm{kN} / \mathrm{m}^{2}$ to the unit $\mathrm{N} / \mathrm{mm}^{2}$ then inputted on the deck plate, side plate and bottom plate. These loads are pressure area loads and each direction is opposite. Load inputting for more details can be seen in Fig. 6 .

The load used to the model is in accordance with the information obtained from the ships general arrangement in the part being modeled, Tier 80 on Bay(3)5 100\% container contents, Tier 82 on Bay(3)5 100\% container contents, and Tier 84 in Bay(5) contents of the container $100 \%$. In other words, the transverse construction of frames 40 - 41 bear the burden of 2.5 stacks of containers.

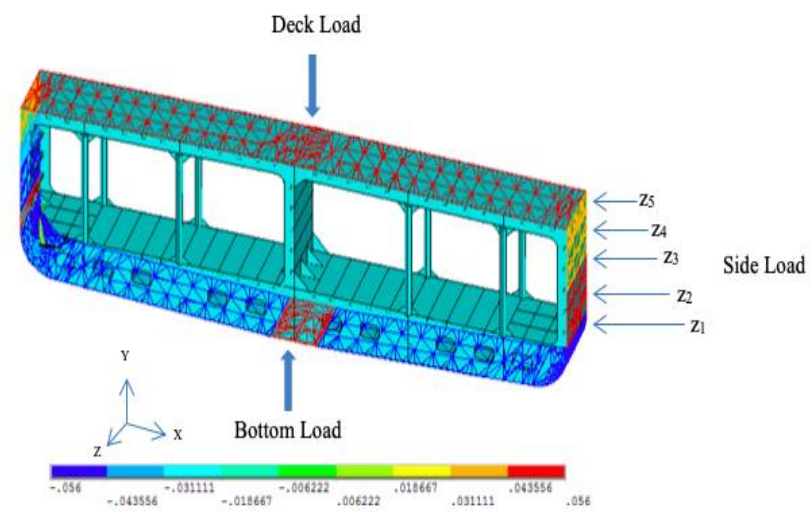

Figure 6. Input conditions of pressure loads on the sides, bottom, and deck of the ship 
Table 1. Variation of loading in several conditions

\begin{tabular}{|c|c|c|c|c|}
\hline Condition & \multicolumn{2}{|c|}{$\begin{array}{l}\text { Container } \\
\text { Capacity }\end{array}$} & $\begin{array}{c}\text { Evenly } \\
\text { Distributed Load } \\
\left(\mathrm{kN} / \mathrm{m}^{2}\right)\end{array}$ & $\begin{array}{c}\text { Total } \\
\text { Deck Load } \\
\left(\mathrm{kN} / \mathrm{m}^{2}\right)\end{array}$ \\
\hline & Вay(3)5 & & \multirow{6}{*}{47.82} & \multirow{6}{*}{69.69} \\
\hline \multirow{5}{*}{1} & Tier $80=$ & $100 \%$ & & \\
\hline & Вay(3)5 & & & \\
\hline & Tier $82=$ & $100 \%$ & & \\
\hline & Bay(3)5 & & & \\
\hline & Tier $84=$ & $100 \%$ & & \\
\hline \multirow{6}{*}{2} & Bay(3)5 & & \multirow{6}{*}{43.835} & \multirow{6}{*}{65.71} \\
\hline & Tier $80=$ & $100 \%$ & & \\
\hline & Bay(3)5 & & & \\
\hline & Tier $82=$ & $100 \%$ & & \\
\hline & Bay(3)5 & & & \\
\hline & Tier $84=$ & $75 \%$ & & \\
\hline \multirow{6}{*}{3} & Bay(3)5 & & \multirow{6}{*}{39.85} & \multirow{6}{*}{61.72} \\
\hline & Tier $80=$ & $100 \%$ & & \\
\hline & Bay(3)5 & & & \\
\hline & Tier $82=$ & $100 \%$ & & \\
\hline & Bay(3)5 & & & \\
\hline & Tier $84=$ & $50 \%$ & & \\
\hline \multirow{6}{*}{4} & Bay(3)5 & & \multirow{6}{*}{35.865} & \multirow{6}{*}{57.74} \\
\hline & Tier $80=$ & $100 \%$ & & \\
\hline & Bay(3)5 & & & \\
\hline & Tier $82=$ & $100 \%$ & & \\
\hline & Bay(3)5 & & & \\
\hline & Tier $84=$ & $25 \%$ & & \\
\hline & Bay(3)5 & & & \\
\hline & Tier $80=$ & $100 \%$ & & \\
\hline & Bay(3)5 & & & \\
\hline 5 & Tier $82=$ & $100 \%$ & 31.88 & 53.75 \\
\hline & Bay(3)5 & & & \\
\hline & Tier $84=$ & $0 \%$ & & \\
\hline & Bay(3)5 & & & \\
\hline & Tier $80=$ & $100 \%$ & & \\
\hline 6 & Bay(3)5 & & & \\
\hline 6 & Tier $82=$ & $75 \%$ & 27.895 & 49.76 \\
\hline & Bay(3)5 & & & \\
\hline & Tier $84=$ & $0 \%$ & & \\
\hline & Bay(3)5 & & & \\
\hline & Tier $80=$ & $100 \%$ & & \\
\hline 7 & Bay(3)5 & & 2301 & 1570 \\
\hline 7 & Tier $82=$ & $50 \%$ & 23.91 & 45.18 \\
\hline & Bay(3)5 & & & \\
\hline & Tier $84=$ & $0 \%$ & & \\
\hline & Bay(3)5 & & & \\
\hline & Tier $80=$ & $100 \%$ & & \\
\hline 8 & Bay(3)5 & & & 7170 \\
\hline 8 & Tier $82=$ & $25 \%$ & 19.925 & 41.79 \\
\hline & Bay(3)5 & & & \\
\hline & Tier $84=$ & $0 \%$ & & \\
\hline & Bay(3)5 & & & \\
\hline & Tier $80=$ & $100 \%$ & & \\
\hline 0 & Bay(3)5 & & 1504 & 3781 \\
\hline 9 & Tier $82=$ & $0 \%$ & 15.94 & 37.81 \\
\hline & Bay(3)5 & & & \\
\hline & Tier $84=$ & $0 \%$ & & \\
\hline & Bay(3)5 & & & \\
\hline & Tier $80=$ & $75 \%$ & & \\
\hline 10 & Bay(3)5 & & & 3383 \\
\hline & Tier $82=$ & $0 \%$ & 11.955 & 33.83 \\
\hline & Bay(3)5 & & & \\
\hline & Tier $84=$ & $0 \%$ & & \\
\hline & Bay(3)5 & & & \\
\hline & Tier $80=$ & $50 \%$ & & \\
\hline 11 & Вay(3)5 & & 707 & 2094 \\
\hline 11 & Tier $82=$ & $0 \%$ & 7.97 & 29.84 \\
\hline & Bay(3)5 & & & \\
\hline & Tier $84=$ & $0 \%$ & & \\
\hline
\end{tabular}

Table 2. Changes in ship draft (T) and bottom load due to variations in deck load

\begin{tabular}{ccc}
\hline $\begin{array}{c}\text { Load } \\
\text { Condition }\end{array}$ & $\begin{array}{c}\text { Draft (T) } \\
(\mathbf{m})\end{array}$ & $\begin{array}{c}\text { Bottom Load } \\
\left(\mathbf{k N} / \mathbf{m}^{\mathbf{2}}\right)\end{array}$ \\
\hline $\mathbf{1}$ & 4.62 & 69.69 \\
$\mathbf{2}$ & 4.22 & 65.705 \\
$\mathbf{3}$ & 3.82 & 61.72 \\
$\mathbf{4}$ & 3.43 & 57.735 \\
$\mathbf{5}$ & 3.03 & 53.75 \\
$\mathbf{6}$ & 2.63 & 49.765 \\
$\mathbf{7}$ & 2.23 & 45.78 \\
$\mathbf{8}$ & 1.83 & 41.795 \\
$\mathbf{9}$ & 1.43 & 37.81 \\
$\mathbf{1 0}$ & 1.03 & 33.825 \\
$\mathbf{1 1}$ & 0.64 & 29.84 \\
\hline
\end{tabular}

Next is the calculation of container weight (tons) which is then defined as uniform load $\left(\mathrm{kN} / \mathrm{m}^{2}\right)$. This load will then be included in the model. In the model, the load variations are given by varying the contents of the containers ranging from $100 \%$ to $0 \%$ with a stack of containers reaching 3 stacks, this is conducted to determine the deflection characteristics and stresses in ship construction. For more details, see Table 1.

By varying the load as shown in Table 1 , the load on the bottom of the ship will be affected by reducing the contents of the container. Then the ship's draft $(\mathrm{T})$ must be decreased so that the deck load value is the same at the bottom load value. The changes in the draft due to load variations were shown in Table 2.

\section{Numerical Results}

After calculating the load, the transversal strength of the ship is analyzed by using the structural response, such as the change in the shape of the ship's structure or displacement and stress due to external loads acting on the ship.

\subsection{Stress on ships structure}

Based on the simulation results, the value of the working stress that occurs at maximum load conditions is 2.5 stack (stack) of containers to the top, the stress that occurs is $140.631 \mathrm{~N} / \mathrm{mm}^{2}$ on deck and $89.729 \mathrm{~N} / \mathrm{mm}^{2}$ on bottom of the ship as shown in Fig. 7.

The greatest stress occurs due to external loads acting on the ship according to Fig. 7 is on the deck, precisely on the deck beam. The stress does not exceed the stress allowed by BKI rules, so the results of the analysis by using FEM meet the specified standards. The results of the recapitulation of stress in the x-direction can be seen in Table 3.

After analyzing the stress on the ship structure during maximum load conditions, an analysis is also carried out by varying the load according to Table 1 . The results of the structural response analysis caused by the variation of loading were shown in Fig. 8. 


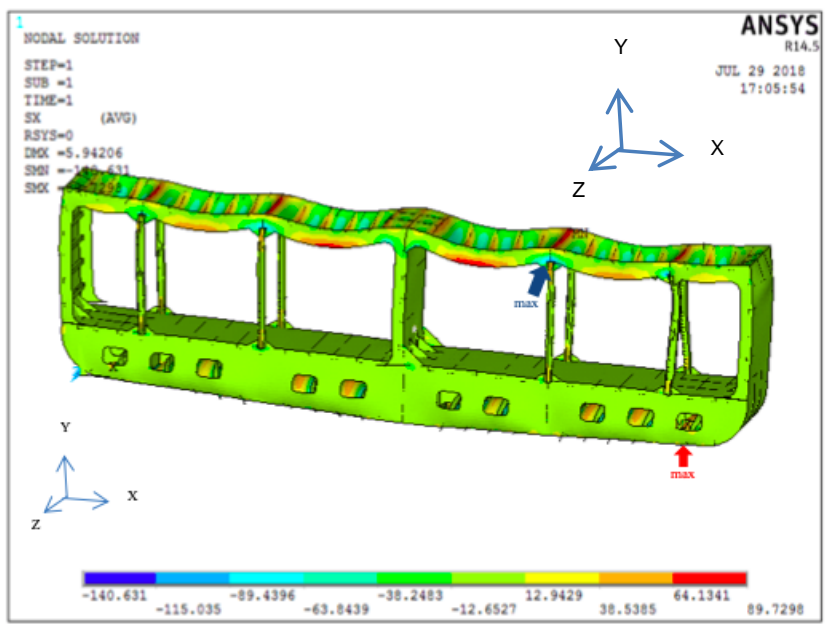

Figure. 7 Behavior and stress distribution due to loading

Table 3. Recapitulation of stress in $\mathrm{x}$-direction

\begin{tabular}{cc}
\hline \multicolumn{2}{c}{ Normal Stress $\left(\mathbf{N} / \mathbf{m m}^{2}\right)$} \\
\hline Deck $($ deck beam $)$ & Bottom $($ bottom plate $)$ \\
\hline$-140.63<150$ Eligible & $89.729<150$ Eligible \\
\hline
\end{tabular}

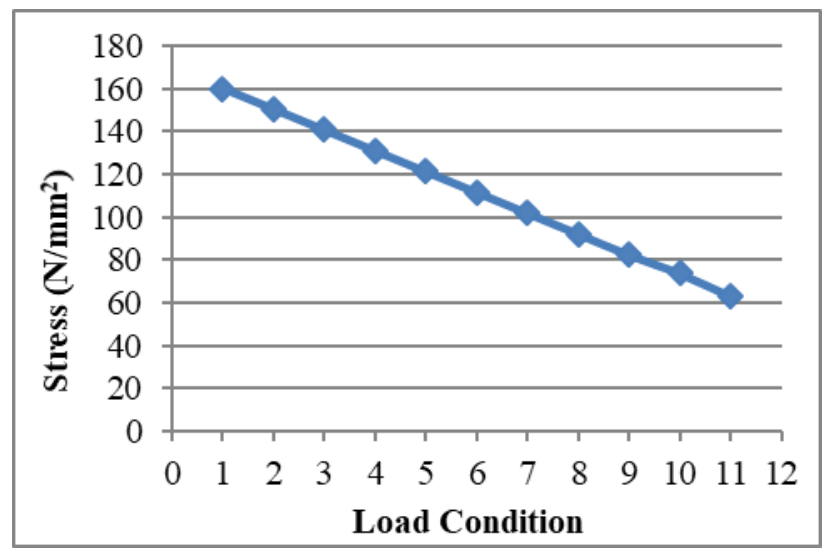

Figure 8. The Relation between load variation and stress

\subsection{Deformation in ships structure}

Based on the analysis result, the deformation that occurs in the transverse construction of the ship given a maximum loading of 2.5 stack containers to the top was shown in Fig. 9. The color gradation in Fig. 9 shows the amount of deformation experienced by ship construction. The red color depicts that in the construction part occur a large deformation while the green color represents smaller or relatively fixed deformations. Maximum deformation occurs in the deck beam with a value of $2.866 \mathrm{~mm}$.

In addition to analyzing the structural deformation at maximum loading conditions, an analysis was also conducted on several loading variations in order to determine the response of the ship structure due to loading. The variations given in the model were shown in Table 1. The response of the structure caused by the variation of loading was shown in Fig. 10.

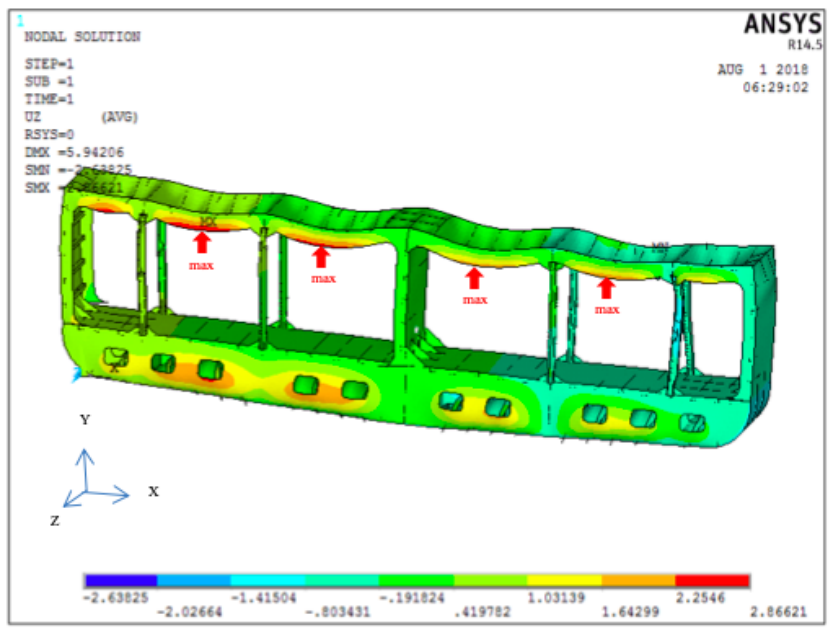

Figure 9. Deformation gradation in ship construction

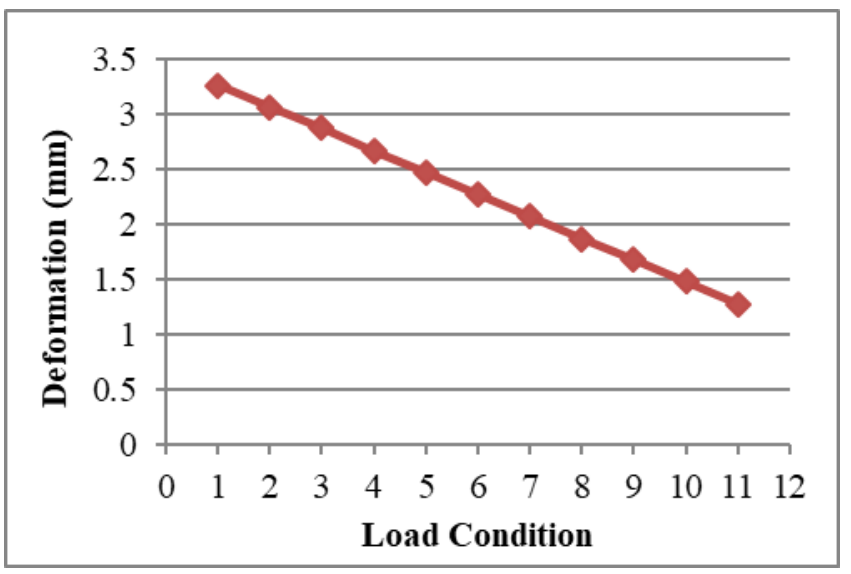

Figure 10. The Relation between load variation and deformation

Table 4. Stress ratio at maximum load conditions

\begin{tabular}{cccc}
\hline Load & $\begin{array}{c}\sigma_{\text {working }} \\
\left(\mathrm{N} / \mathrm{mm}^{2}\right)\end{array}$ & $\begin{array}{c}\sigma_{\text {permissible }} \\
\left(\mathrm{N} / \mathrm{mm}^{2}\right)\end{array}$ & Stress Ratio \\
\hline Maximum & 140.63 & 150 & 0.937 \\
\hline
\end{tabular}

Based on the curve was shown in Fig. 10, it is known that due to constant load reduction, the deformation that occurs also experiences a linear reduction, as seen on the graph of the average deformation reduction of $0.18 \mathrm{~mm}$.

\subsection{Stress ratio}

Normal stress acting on the transverse construction of ships due to external loads must not exceed $150 / \mathrm{k}\left[\mathrm{N} / \mathrm{mm}^{2}\right]$, where $\mathrm{k}$ is a material factor whose value is equal to 1 . This value is obtained based on BKI Vol II 2016 rules that the value of $\mathrm{k}$ is taken 1 for normal strength steel hull construction.

Stress Ratio is obtained by comparing the stresses that occur in construction due to external loads acting on the ship. Based on Table 4, the stress acting on the ship still eligible according to BKI rules because the stress ratio value is still smaller than $1 \quad(<1)$. So, it can be concluded that the transverse construction design of the Container Ship, KM 
Khendaga Nusantara 11 with a maximum load of 2.5 stack containers can be said to be feasible because they are still under the BKI permit stress.

\section{Conclusions}

This research was conducted using Finite Element Method (FEM). Based on the result, this research can be concluded as below:

- The response of the ship structure due to external loads acting on the ship will experience deformation with the largest value occurring on the deck beam that is $2.86 \mathrm{~mm}$ and ship construction experiences the greatest stress on the deck precisely on the deck beam about -140.63 $\mathrm{N} / \mathrm{mm}^{2}$ and at the bottom precisely on the base plate area about $89.73 \mathrm{~N} / \mathrm{mm}^{2}$.

- The strength of transverse construction of the ship with all the loads located above the deck and below the deck consisting of void tanks can be said to be eligible, with a maximum load of 15 container units or 2.5 stacks above (1 Row consist 6 units) because under these conditions, the stress which occurs in construction is still below the permissible stress.
- Stress ratio occurs to ship construction due to external loads working on ships is still smaller than $1(<1)$. The largest stress ratio occurs at the maximum load condition of 15 container units or 2.5 stacks (stack) which is 0.93753 .

\section{References}

[1] Shama, Mohamed. 2013. Buckling of Ship Structures. Alexandria University, Egypt.

[2] Molland, Anthony F. 2008. Maritime Engineering Reference Book. Elsevier Butterworth-Heinemann: Oxford.

[3] Rasyid, Daniel Muhammad. 2000. Strength of Ship Structure. Pradnya Paramita. Jakarta. [in Bahasa].

[4] Hughes, Owen F., dan Paik J.K. 2010. Ship Construction Analysis and Design. The Society of Naval Architecture and Marine Engineers: New Jersey.

[5] Biro Klasifikasi Indonesia. 2016. Rules For The Classification And Construction Seagoing Steel Ship, Volume II. BKI. Jakarta.

[6] Patnaik, Surya N., and Dale A Hopkins. 2004. Strength of Materials. Elsevier. Amsterdam.

[7] Gross, Dietmar. 2011. Engineering Mechanics 2 "Mechanics of Materials". Springer. London

[8] Susatio, Yerri. 2004. Basics of Finite Element Method. Andi. Yogyakarta. [in Bahasa]

[9] Bhavikatti, S.S. 2005. Finite Element Analysis. New age International Publisher. New Delhi. 